\title{
Uma Aproximação Semântica aos Conceitos de Urbano, Rural e Cooperativa
}

\author{
Francisco José Batista de Albuquerque ${ }^{1}$ \\ Carlos Eduardo Pimentel \\ Universidade Federal da Paraíba
}

\begin{abstract}
RESUMO - No planejamento de políticas públicas vinculadas ao desenvolvimento rural, a definição de alguns conceitos, como os de ambiente rural, urbano e cooperativa são sumamente importantes. Considerando que a Psicologia pouco contribuiu no desenvolvimento rural, objetivou-se conhecer os significados que são socialmente atribuídos aos conceitos de rural, urbano e cooperativa. Através da participação de 318 estudantes do ensino médio, do estado da Paraíba (Brasil), pôde-se verificar que o rural é entendido como essencialmente rurícola; o ambiente urbano, por outro lado, é concebido como oposto ao rural e o conceito de cooperativa, tem uma significação eminentemente positiva, que engloba palavras como ajuda e união. Destaca-se a necessidade de se refletir criticamente acerca das políticas para o desenvolvimento rural e de pesquisas na área que contribuam para aclarar questões relacionadas ao desenvolvimento de propostas que contemplem o rural na sua totalidade, proporcionando rever conceitos e avaliar práticas de ações governamentais.
\end{abstract}

Palavras-chave: políticas públicas; conceitos; rural; urbano; cooperativa.

\section{A Semantic Approach to the Concepts of Urban, Rural and Cooperative}

\begin{abstract}
When it comes to the planning of public policies linked to the rural development, finding a definition of concepts of rural and urban environments and also of cooperative becomes essentially important. Considering that psychology has barely little contributed to the rural development, this study aimed at identifying the meanings which are socially given to the mentioned concepts. With a sample of 318 high school students from Paraíba (Brazil), it was observed that the rural construct conveyed meanings essentially related to the rural atmosphere; the urban environment was conceived as being the opposite of rural and the concept of cooperative carried a positive meaning, having within it words like 'help' and 'union'. Critical thoughts over the policies for the rural development are urged and so are further studies in the area which may contribute to clarify aspects related to the development of proposals for the rural environment in its totality. The review of some concepts is provided and also the evaluation of some government actions through public policies.
\end{abstract}

Key words: public policies; concepts; rural; urban; cooperative.

A linguagem exerce um papel relevante e indispensável na socio-gênese das interações humanas. A socialização do indivíduo dá-se principalmente em função dessa ferramenta e não há dúvidas de que sua existência possibilita a invenção e a difusão do conhecimento. O significado é uma das partes fundamentais da linguagem. A necessidade que tem o homem de comunicar-se e de intercambiar informações constitui um dos fatores mais importantes de sua existência e de sua atividade vital. O problema principal da palavra e da linguagem, ou seja, a determinação do seu significado e de sua importância no processo de comunicação tem um valor ingente para a psicologia social (Howitt \& cols., 1992; Pariguin, 1972).

De acordo com Reyes-Lagunes (1993), o significado, na psicologia, tem recebido várias definições, pois se pode concebê-lo como um fator representativo, uma disposição, uma expectativa, uma reação de medição ou um significado subjetivo ou psicológico, o qual constitui uma interpretação

1 Endereço: Universidade Federal da Paraíba, Departamento de Psicologia, Cidade Universitária, João Pessoa, PB, Brasil 58059-900. E-mail: frajoba@uol.com.br interna da realidade, refletindo o conjunto de emoções, lembranças, pensamentos, sentimentos e sensações. Além disso, atua como mediador entre os objetos sociais e as condutas em relação a eles. Este processo se torna complexo e dá lugar às redes de significações, ou como se tratará no presente trabalho, às redes semânticas. Tais redes constituem o significado que tem, para os atores sociais, qualquer objeto do seu entorno (Figueroa, Gonzáles \& Solis, 1981).

A investigação atual em psicologia confere ênfase especial ao estudo dos processos cognitivos, a forma com que se estrutura a informação apreendida e sua utilização. Para o Modelo de Redes Semânticas Naturais (Figueroa \& cols., 1981), a informação armazenada se organiza em forma de redes associativas, nas quais as palavras, eventos ou representações, formam relações que em conjunto constituem significados. Estes significados são desenvolvidos desde o conjunto de informações que desenvolvemos e que nos auxiliam a conhecer e a participar da realidade. A formação dos conceitos que temos sobre qualquer coisa segue este processo de associação de significados, que é considerada uma tendência natural da cognição, da acumulação de conhecimentos sobre o mundo (Gardner, 1996). 
Neste sentido, conhecer estes significados resulta pertinente para a análise das políticas públicas, porque podem refletir a maneira como os agentes governamentais, responsáveis pelos seus planejamentos, compreendem conceitos do objeto social envolvido. No Brasil, considera-se que o Estado exerce um papel crucial na economia e na política de redistribuição de rendas e de diversificação do crescimento regional. Sendo um país de economia complexa, no qual os serviços correspondem aproximadamente a $2 / 3$ da formação do Produto Nacional Bruto (PNB), o que demonstra uma economia moderna e ao mesmo tempo com cerca de $18 \%$ de sua população residindo na área rural (IBGE, 2002), as decisões sobre onde e quando alocar recursos, que em última análise constituem o âmago das políticas públicas, jogam um papel fundamental no desenvolvimento sócio-econômico.

Apesar desta modernidade, que também chegou ao interior do país, posto que as economias das pequenas cidades brasileiras, hoje em dia, não dependem exclusivamente da agricultura, e sim dos serviços (Albuquerque, Lôbo \& Raymundo, 1999), ainda se confunde o rural com o agrário, como se fossem sinônimos. Podem ser citados, por exemplo, setores como as pequenas empresas, o comércio, os grupos culturais, os setores de serviços e os aposentados, que constituem, atualmente, novas fontes de renda dos pequenos municípios brasileiros. Assim, quando se fala em desenvolvimento rural, muitas vezes se está falando em desenvolvimento agrário, na parte do rural mais ligada à agricultura e pecuária, e não ao conjunto da economia produtiva da região (Albuquerque, 2001). Como mostrou Albuquerque $(1994,1997,1999)$ as cooperativas têm sido utilizadas para incrementar o desenvolvimento agrário, mas se apresentam como organizações complexas, difíceis de administrar e conseqüentemente de obter êxito, servindo muitas vezes a interesses personalísticos, em detrimento da coletividade em nome da qual foram destinados os benefícios. Em função disso, buscou-se conhecer qual o conjunto de significados que são atribuídos a termos cruciais no processo decisório, e que representam, provavelmente, o apoio social às decisões políticas. Portanto, este trabalho se interessou, fundamentalmente, em efetuar uma análise semântica de conceitos implicados na implementação de políticas públicas; precisamente, intentou desvelar os significados psicossociais dos conceitos de cooperativa, rural e urbano.

\section{Cognição e redes semânticas}

Turner (1994) afirma que, nos últimos anos, a psicologia social tem investigado as estruturas e processos pelos quais os sujeitos conhecem o mundo, pois se verifica, depois dos anos de 1970, a atenção dos pesquisadores orientada para a compreensão dos processos cognitivos. Acerca desta atividade, Thagard (1998) menciona que o interesse da psicologia, e também da ciência computacional, em relação à natureza dos conceitos, foi incrementado velozmente na metade da década de 1970, quando os pesquisadores introduziram termos como "estrutura" e "esquema", na descrição de novas formas de avaliação da natureza dos conceitos.

Porém, Fiske e Taylor (1991) assinalam que, desde os tempos de Lewin, os psicólogos sociais mantêm que o comportamento social deve ser entendido como uma função da percepção que as pessoas têm do mundo, sustentando que tal percepção deve-se às interpretações dos estímulos oriundos do meio. Atualmente, evidencia-se a influência lewiniana na orientação sócio-cognitiva, cujas pesquisas têm-se dedicado ampla e profundamente à investigação e compreensão dos mecanismos mentais em interação com o social, ao analisar os processos psicossociais pelos quais selecionamos, interpretamos e usamos com tanta facilidade a informação proveniente do meio (Jacinto \& Ortiz, 1997). De fato, notase uma forte tendência, nos autores, para considerarem a perspectiva cognitivista como o ponto de vista preponderante nas pesquisas atuais na psicologia e, especificamente, na psicologia social (Echebarría, 1991; Estramiana, 1995; Morales \& cols., 1994; Roazzi, 1999; Rodrigues, Assmar \& Jablonski, 2000; Sabucedo, D'Adamo \& Beaudoux, 1997; Smith \& Mackie, 1995; Zajonc, 1968). Na psicologia social, a teoria do equilíbrio, a teoria da dissonância cognitiva, e demais teorias de consistência cognitiva, entre outras, são exemplos dessa tendência (Zajonc, 1968).

Tulving (1972) explica que a técnica de redes semânticas deriva dos estudos da memória em longo prazo no campo da psicologia cognitiva, em que vários autores (Vera-Noriega, Laga-Castro \& Hernández-Loya, 1998) situam a memória semântica. A memória é considerada o cerne da cognição (Mussen, Conger, Kagan \& Huston, 1995), porquanto que se não existisse memória a atividade cognitiva seria inútil.

Coerente com a concepção de memória adotada no presente estudo, Allan Collins e Ross Quillian, em 1969, publicam os resultados do seu estudo seminal, o qual sugere a memória semântica como organizada numa estrutura hierárquica (Sternberg, 2000). De acordo com Tulving (1972), que concebe um modelo para a memória segundo o conteúdo a ser processado, seja na memória episódica, semântica ou procedural, a memória semântica é a memória necessária para o uso da linguagem, pois organiza o conhecimento que as pessoas possuem sobre as palavras e outros símbolos verbais, seus significados e referentes acerca das relações entre eles e as regras, fórmulas e algoritmos para a manipulação dos símbolos, conceitos e relações. Lachman, Lachman e Butterfield (1979) concluem que a memória semântica leva em conta a capacidade humana para construir a realidade, numa interpretação interna, e é através desta que se interpretam as experiências passadas, realizam-se predições e atribuições de causalidades e também se conectam idéias velhas dentro de combinações novas. Bracham (1979) afirma que a idéia de redes semânticas é a idéia moderna da memória humana. Segundo Morales e cols. (1994), a memória semântica é constituída por representações de conceitos ou conhecimentos gerais. Coerentemente, Sternberg (2000) assinala que a memória semântica trabalha com conceitos, características e idéias associadas. Grzib e Briales (1996), por sua vez, ressaltam que é na memória semântica que os signos lingüísticos estão armazenados. A importância de todo este processo reside no fato de que o conhecimento se organiza sob a forma de redes de significados (Abdounur, 2002). Segundo as palavras do autor:

Esta idéia, que se opõe à de construção linear ou vertical do conhecimento, vem conquistando importância crescente nos terrenos da epistemologia e da didática. No dizer de Capra, "agora 
estamos nos movendo em direção à metáfora do conhecimento como uma rede, um tecido onde todos os elementos encontramse conectados". (Abdounur, 2002, pp. 102-103)

Portanto, a técnica de redes semânticas oferece um meio empírico de acesso à organização mental do conhecimento. Dessa forma, pode proporcionar dados referentes à organização e interpretação interna dos ambientes rural e urbano, assim como ao significado e à representação interna do cooperativismo. Também, indica como a informação foi percebida individualmente no curso da composição da formação dos conceitos e fornece indícios fundamentais acerca da tendência a atuar com base nesse "universo cognitivo". No sentido empregado por Krech, Crutchfield e Ballachey (1975), sendo tanto o ambiente físico quanto o social, apreendido pelo indivíduo, de modo que as cognições refletem esses ambientes, agindo como estruturadas mentais que facilitam o entendimento do mundo social e o enfrentamento dos problemas. Sendo assim, conclui-se que existem problemas sociais que provocam necessidades comuns às pessoas, levando-as a organizar o conhecimento angariado empiricamente com o fim de atuar, eficazmente, frente a estas situações.

\section{Limites conceituais: rural $\mathbf{x}$ urbano}

Segue-se, dos argumentos precedentes, a relevância de se estudar os significados com os quais lida o pesquisador social, ao considerar a dificuldade proporcionada pelas definições de rural e urbano (Albuquerque, 2001). Tendo isso em vista, Berry, Markee, Fowler e Giewat (2000) chamam a atenção para a influência da definição desses conceitos na implementação de projetos de políticas na educação, nas decisões jurídicas, nos serviços de saúde pública e no desenvolvimento da própria região. Desafortunadamente, porém, "os significados de urbano e rural freqüentemente permanecem vagos $e$ imprecisos" (Slack, 1990; Flora \& cols., 1992; Andranovich \& Riposa, 1994, conforme citados por Berry \& cols. 2000, p. 94). Uma explicação para tal pode ser concebida, pois, sobretudo nos grandes centros, o ambiente rural é percebido como um todo homogêneo e subdesenvolvido, refletindo informações distorcidas que não correspondem aos fatos. Adite-se a isso as definições apresentadas em dicionários, em que se concebe o rural usualmente a partir deste ângulo, tendo sinônimos depreciativos, como atrasado, rústico, rude ou agrário (Albuquerque, 2001).

Albuquerque e Cirino (2001) destacam que a psicologia deve e pode aportar conhecimentos que ajudem as pessoas, habitantes do rural, a relacionar-se melhor no ambiente em que vivem. A contribuição da psicologia social pode ser de grande importância para a facilitação e o desenvolvimento do meio rural, que vive hoje um rápido processo de transformação, a partir das mudanças sócio-culturais do mundo moderno. Os autores salientam ainda que, partindo do entendimento da realidade rural, esta se tornaria um vasto campo de trabalho para as pessoas, inclusive para o profissional de psicologia. Realmente, a psicologia é capaz de oferecer diversos serviços necessários e específicos da área mental, como trabalhos sobre avaliação de políticas públicas, sobre cooperativismo e associacionismo, nas cooperativas, nos assentamentos agrários e na agroindústria, entre outros.
Tais serviços podem beneficiar a limitação do caos que se contempla nas grandes cidades brasileiras de hoje, na medida em que sejam ofertadas melhores condições de vida nos pequenos municípios, atraindo de volta os que por necessidade partiram, e fixando ali aqueles que não desejam partir.

\section{Cooperativas: valor semântico ou valor prático?}

Estas empresas ou organizações, apesar da crescente expansão em todos os países do mundo, carecem de estudos que enfoquem aspectos psicossociais indispensáveis para o seu êxito. Assim como aconteceu com o ambiente rural, a psicologia pouco fez para a compreensão das cooperativas, da sua dinâmica grupal e das forças psicológicas atuantes entre os seus membros (Albuquerque, 1994). Entretanto, alguns estudos, antes mencionados, colocaram questões interessantes que servem de ponto de partida para uma análise crítica dos incentivos governamentais e da maneira como é formado esse empreendimento.

Tal análise inicia-se pelo fato de que as organizações cooperativas são geralmente percebidas, pelo senso comum, como muito distintas das demais organizações, e por carregarem uma imagem positiva por grande parcela da população e dos agentes governamentais de desenvolvimento. Podem ser encontrados alguns exemplos de cooperativas que têm demonstrado bom desenvolvimento econômico. Em geral estas cooperativas atuam como prestadoras de serviços nas áreas de saúde, comércio e crédito. Aproveitam-se dos incentivos legais que, por exemplo, lhes dispensa o pagamento do imposto sobre a renda, o que gera um diferencial financeiro importante frente às outras empresas que prestam o mesmo serviço e que não dispõem desse apoio. Entretanto, à parte desse aspecto financeiro, chama a atenção o fato destas cooperativas não exercitarem trabalhos em conjunto entre os seus sócios; ou seja, a tão esperada cooperação ou atividade cooperativa. Elas se dedicam, por outro lado, a intermediar relações de prestação de serviços sem que os sócios tenham o menor contato entre si, muitas vezes competindo pelos mesmos clientes. A questão que se coloca é se estas empresas correspondem ao modelo em nome do qual ideologicamente foram construídas e que em seu nome recebem os incentivos governamentais. Retirem-se os incentivos e estas cooperativas aparecem iguais, sem distinção das outras empresas do ramo.

Ressalte-se a grande influência do valor semântico agregado à palavra cooperação ou atividade cooperativa, haja vista que, desde cedo, a família, a religião e os professores educam-nos e nos incutem o valor do trabalho conjunto e coletivo. Além disso, quando se reporta ao surgimento das cooperativas, vê-se que ele se deu no sentido de servir como um bem social, como uma alternativa em prol dos trabalhadores, artesões e pequenos produtores, face às incertezas e crueldades do mercado. Dessa maneira, torna-se nítido que o nome "cooperativa" não foi escolhido à toa, para designar essa organização cujo fim é tão meritório, pelo menos aparentemente. No entanto, não se deve analisá-la de forma superficial, pois, não obstante seu valor semântico e o objetivo histórico motivador do seu surgimento, tais organizações, segundo dados empíricos, são mais tendentes a malograr do que a obter êxito (Albuquerque, 1994, 1997, 
1999; Albuquerque \& Cirino, 2001). Esta situação acontece apesar dos incentivos estratégicos governamentais e, por conseguinte, dos fortes apoios financeiros por parte do Estado, destinando-lhes recursos que poderiam ser mais bem aproveitados se fossem destinados à educação, saúde ou segurança pública, por exemplo.

Em resumo, se analisar problemas sociais faz parte da agenda prática do cientista social e se as cooperativas são organizações que deixam a desejar em termos de êxito empresarial ou social, cumpre indagar por que, apesar de todas as evidências de fracassos e dificuldades administrativas que geram, estas organizações ainda conseguem captar recursos estatais, com forte apoio de grande parte da população. Pensamos que parte da explicação radica na própria palavra. Como dito antes, cooperar é visto como algo positivo, associandose a esta palavra significados muito valorados socialmente. Assim, ocorre um traspasse entre o valor da palavra e o tipo de empresa ou organização, de forma alienada, desvinculando o significado do objeto, e permitindo que desta separação se aproveitem, em nome dos deserdados sociais, aqueles, mais avisados, que bem poderiam deixar os benefícios do Estado para os que realmente deles necessitam. Portanto, analisar o que as pessoas pensam e que relações estabelecem entre as palavras cooperativismo, rural e urbano, pode ajudar a entender como as decisões políticas são tomadas, que mecanismos mentais estão envolvidas nos processos decisórios que afetam a todos nós, e dos quais, muitas vezes, nos omitimos, ou não nos apercebemos de sua importância.

\section{Método}

\section{Participantes}

Escolheu-se investigar as redes semânticas desenvolvidas por estudantes de nível médio, tanto de ambiente urbano quanto rural, por se considerar que esses participantes constituem uma amostra leiga, não contaminada com informações de cunho técnico, sobre os temas pesquisados, representando, assim, características similares às da população brasileira, em geral, no que tange aos conceitos.

Esta amostra, não-probabilística, compôs-se de 318 estudantes secundaristas do estado da Paraíba (Brasil), que se submeteram voluntariamente à aplicação dos instrumentos. Para efeito de comparação de dados, dividiu-se essa amostra total em dois grupos naturais. O Grupo I constituiu a amostra urbana, com 165 alunos de colégios públicos, situados na cidade de João Pessoa. A média de idade dos participantes foi de 23 anos $(D P=4,87)$. O Grupo II formou a amostra rural, com 153 alunos de colégios públicos, de comunidades rurais próximas da cidade de Areia (dista $120 \mathrm{Km}$ da capital). A média de idade desses alunos foi de 17 anos $(D P=2,41)$.

\section{Instrumento}

A construção do instrumento baseou-se no Modelo de Redes Semânticas Naturais, proposto por Figueroa e cols. (1981). O instrumento consta de quatro páginas, a primeira informando ao respondente sobre a pesquisa e exemplificando o procedimento esperado e as três páginas seguintes contendo as palavras-estímulo: rural, urbano e cooperativa.
Cada uma dessas palavras ou estímulos foi apresentada impressa na parte superior (vertical) de uma folha de papel tamanho ofício. Optou-se por deixar um espaço em branco na folha, para o participante escrever cada uma das palavras associadas livremente com o estímulo. A quarta e última página visaram colher dados pessoais do participante (idade, local de residência e série que cursava) e finalizando com agradecimentos pela colaboração na pesquisa.

\section{Procedimentos}

Em ambos os grupos, foram efetuadas aplicações dos instrumentos coletivamente, em sala de aula, possibilitando um número variado de participantes por cada aplicação. Inicialmente, seguindo um procedimento padrão, apresentou-se o objetivo da visita dos pesquisadores e, em seguida, foram transmitidas oralmente as instruções para o procedimento do respondente, apresentando-se um exemplo de como os participantes deveriam proceder com a folha, onde constava o conceito. Explicou-se que os conceitos deveriam ser definidos por meio de "palavras soltas" (substantivos, adjetivos e verbos), mas nunca por meio de artigos, pronomes, preposições ou qualquer outra partícula. Quando havia a necessidade de maiores esclarecimentos utilizava-se o quadro negro e um outro exemplo era demonstrado. Foi solicitado que os participantes dessem um máximo de dez definidoras (palavras) por conceito, para isso tinham três minutos para a associação livre e mais um minuto para a hierarquização das palavras.

\section{Análise dos dados}

Os dados foram processados de acordo com o procedimento para se obter os parâmetros da técnica de Redes Semânticas Naturais, a saber: Tamanho da Rede (TR), Núcleo da Rede (NR), Peso Semântico (PS) e Distância Semântica Quantitativa (DSQ). O TR é obtido através do número total de definidoras (no caso, palavras utilizadas para definir os conceitos de Urbano, Rural e Cooperativismo). O PS de cada definidora se obtém somando a ponderação das frequiências pela hierarquização, em que se assinala o número um à palavra ou definidora mais próxima e se multiplica por dez, o número dois à segunda palavra mais próxima e se multiplica por nove, três para a terceira mais próxima e se multiplica por oito até chegar ao número dez, que é multiplicado por um. O NR se consegue mediante as dez definidoras com peso semântico mais alto. Estas definidoras, que conformam o NR, são as que melhor representam o conceito. A DSQ se obtém através das definidoras do NR, assinalando à definidora, com peso semântico mais alto, o valor $100 \%$, e as demais porcentagens sendo obtidas através de uma regra de três simples (Reyes-Lagunes, 1993).

\section{Resultados}

Os resultados ora apresentados fazem referência ao núcleo da rede de cada conceito analisado, incluindo, respectivamente, seus pesos semânticos e as distâncias semânticas quantitativas. O núcleo da rede (NR) é constituído pelas definidoras mais freqüentes e com maiores pesos semânticos, 
o que compreende as definidoras que na sua inter-relação formariam o significado do conceito. O peso semântico (PS) é especialmente útil na comparação dos totais absolutos que o grupo atribui aos conceitos e serve para a apreciação da variabilidade intergrupos. Quanto à distância semântica quantitativa (DSQ), trata-se de um indicador da variabilidade intragrupo. Finalmente, a falta de correspondência conceitual é o parâmetro mais simples que se pode observar, servindo também para realizar comparações entre os grupos.

O conceito de cooperativa foi definido, de forma geral, com conceitos tidos como socialmente valorizados. A definidora com maior peso semântico foi ajuda, mas apareceram também definidoras a ela relacionadas fortemente, como é o caso de cooperação e companheirismo. Surgiram, ainda, outras definidoras associadas à palavra cooperativismo, como união, grupo, trabalho, organização, reunião e associação que conformaram o núcleo da rede urbana e rural (Tabela 1).

Tabela 1. Resultados das redes semânticas para o conceito de cooperativa

\begin{tabular}{lccccc}
\hline \multicolumn{3}{c}{ Urbano } & \multicolumn{3}{c}{ Rural } \\
\hline \multicolumn{1}{c}{ NR } & PS & DSQ & NR & OS & DSQ \\
\hline Ajuda & 498 & $100 \%$ & Ajuda & 617 & $100 \%$ \\
Grupo & 477 & $95,78 \%$ & União & 497 & $80,55 \%$ \\
Trabalho & 454 & $91,16 \%$ & Cooperação & 446 & $72,30 \%$ \\
União & 445 & $89,36 \%$ & Trabalho & 301 & $48,80 \%$ \\
Cooperação & 408 & $81,93 \%$ & Grupo & 296 & $48,00 \%$ \\
Organização & 161 & $32,33 \%$ & Reunião & 291 & $47,20 \%$ \\
Companheirismo & 154 & $30,92 \%$ & Associação & 258 & $41,81 \%$ \\
\hline
\end{tabular}

Notas: NR=Núcleo da Rede; PS=Peso Semântico; DSQ= Distância Semântica Quantitativa.

No que concerne ao conceito de rural, a palavra campo foi majoritariamente utilizada como definidora principal. Associaram-se, ainda, conceitos inter-relacionados como plantações, ar puro, fazendas, animais, sítios, agricultura, rios, natureza e vegetação, conformando, assim, o núcleo da rede do conceito tanto pelos respondentes do Grupo I (Urbano), quanto pelos do Grupo II (Rural). Percebe-se, por ambos os grupos, um conteúdo de valoração positiva para este ambiente, no que se refere aos aspectos mais ligados à própria natureza, conforme pode ser visto na Tabela 2

Tabela 2. Resultados das redes semânticas para o conceito de rural

\begin{tabular}{lccccc}
\hline \multicolumn{3}{c}{ Urbano } & \multicolumn{3}{c}{ Rural } \\
\hline \multicolumn{1}{c}{ NR } & PS & \multicolumn{1}{c}{ DSQ } & NR & OS & DSQ \\
\hline Campo & 495 & $100 \%$ & Campo & 454 & $100 \%$ \\
Plantações & 445 & $89,90 \%$ & Ar puro & 382 & $84,14 \%$ \\
Fazendas & 400 & $80,80 \%$ & Animais & 364 & $80,20 \%$ \\
Sítios & 294 & $59,40 \%$ & Agricultura & 273 & $60,13 \%$ \\
Rios & 278 & $56,20 \%$ & Natureza & 228 & $50,22 \%$ \\
Agricultura & 201 & $40,60 \%$ & Rios & 211 & $46,47 \%$ \\
Vegetação & 170 & $34,34 \%$ & - & - & \\
\hline
\end{tabular}

Notas: NR=Núcleo da Rede; PS=Peso Semântico; DSQ= Distância Semântica Quantitativa.

Em relação ao conceito de urbano, pode-se observar na Tabela 3, que a palavra cidade foi eleita como a mais importante, isto é, como sendo a que melhor representa esse conceito. No núcleo da rede ainda figuram as definidoras: população, poluição, industrialização, barulho, ruas, violência, pessoas, trânsito e agitação. Chama a atenção o fato de que, diferentemente do que pode ser percebido na Tabela II, aqui aparecem atribuições de conteúdo negativo em ambos os grupos, sendo que, com maior ênfase no grupo constituído pelos que habitam o ambiente rural, para o qual, exceto no que concerne à definidora cidade, todas as demais definidoras apresentam aspectos negativos.

Tabela 3. Resultados da rede semântica para o conceito de urbano

\begin{tabular}{lccccr}
\hline \multicolumn{3}{c}{ Urbano } & \multicolumn{3}{c}{ Rural } \\
\hline \multicolumn{1}{c}{ NR } & PS & \multicolumn{1}{c}{ DSQ } & NR & OS & \multicolumn{1}{c}{ DSQ } \\
\hline Cidade & 794 & $100 \%$ & Cidade & 813 & $100 \%$ \\
População & 490 & $62,22 \%$ & Poluição & 364 & $44,77 \%$ \\
Industrialização & 271 & $34,13 \%$ & Barulho & 345 & $42,43 \%$ \\
Ruas & 252 & $31,74 \%$ & Violência & 201 & $24,72 \%$ \\
Pessoas & 249 & $31,40 \%$ & Trânsito & 190 & $23,40 \%$ \\
Agitação & 229 & $28,84 \%$ & - & - & \\
\hline
\end{tabular}

Notas: NR=Núcleo da Rede; PS=Peso Semântico; DSQ= Distância Semântica Quantitativa.

\section{Discussão}

O conceito de cooperativa, como suposto (Albuquerque, 1999), goza de uma conotação favorável, pois foi constatado que agrega um valor semântico atrativo. Corrobora-se isto quando verificados os núcleos das redes de ambos os grupos, rural e urbano. Estes grupos compartem, sem grandes diferenças, palavras valoradas socialmente. Veja-se, como exemplo, a definidora ajuda, que foi atribuída como a mais representativa tanto para o GI - Urbano, quanto para o GII - Rural, pois teve o maior peso no núcleo das redes rurais e urbanas. Em torno do conceito de cooperativa giram significados positivos, que lhe dão uma atratividade semântica definida por palavras como grupo, união, cooperação, solidariedade, companheirismo.

Como dito, desde cedo os agentes socializadores imprimem às crianças, adolescentes e jovens o valor do trabalho em grupo, como sendo um solo sobre o qual se fomentariam sentimentos de solidariedade, união, ajuda mútua e companheirismo. Esse fenômeno se observa em vários âmbitos de socialização, como nas escolas, através dos trabalhos em equipe, nas universidades, com os grupos de pesquisa, nos esportes, nas famílias e igrejas. Em todas essas instâncias, a cooperação é tida como um valor a se preservar e até mesmo uma norma para o seu bom funcionamento. Dessa forma, conjugar forças para a solução de problemas comuns, como o desemprego no campo e o inchaço nas grandes cidades, revela-se como uma atividade assaz atraente.

A cooperação é um valor não apenas social, mas, principalmente, aquele que melhor possibilita a sobrevivência da espécie humana. Em todas as culturas, em todas as épocas, a cooperação intra e intergrupal têm sido uma força de preservação, tanto da cultura comum como da própria raça. Entretanto, é importante salientar a distinção entre cooperação e cooperativa. Enquanto a cooperação é um valor social de elevado teor para a manutenção de valores e da espécie, a cooperativa é uma tentativa de operacionalização 
desse conceito em forma de instituição. Ora, disso decorre o problema. Esta passagem, de um valor social para a sua operacionalização, tem deixado uma distância muito elevada entre os princípios que norteiam a cooperação e a sua efetivação através do cooperativismo.

Em estudos anteriores, citados neste texto, temos analisado várias experiências cooperativas e demonstrado o quão difícil é um desses empreendimentos que funcione de modo próprio. Todos recorrem às burras do Estado ou de algum outro agente financiador externo para se manterem atuando. Então, torna-se legítimo investigar os porquês não só da propensão ao fracasso dessas organizações, enquanto entidades produtivas e financeiras, mas também da manutenção de sua aura de positividade, que vai de encontro a todas as evidências.

Aqui entramos em um terreno mais sutil, que é o da percepção social. Ou seja, depois de tantas análises sobre estas organizações, em que se constatam as fragilidades na aplicação dos seus nobres princípios, as dificuldades em manter um processo administrativo coerente com seus ideários e o fracasso financeiro da sua grande maioria, pode-se perguntar como ainda mantêm a sua popularidade. As explicações variam em diversos tons, porém todos formam um conjunto compreensível.

Em primeiro lugar, deve-se entender que este tipo de organização não está isenta de conteúdo ideológico. Os que defendem o cooperativismo como uma solução para a crise econômica, o desemprego e outros problemas, esposam princípios com os quais todos concordamos e que, em última instância postulam o desenvolvimento social justo e eqüitativo, de modo a possibilitar a todos o acesso à qualidade de vida e cidadania. O problema é que entre o desejo e a realização se encontra um fosso. Mas esta discussão não é nova. Não foi à toa que se cunhou de socialistas utópicos autores como Fourrier, Proudhom, Orwell e outros, que defendiam o cooperativismo como mola propulsora das mudanças nas estruturas sociais. Eram contestados como sendo utópicos, porque se as cooperativas se assentavam sobre uma base historicamente determinada, estavam destinadas a seguir o seu caudal e não poderiam mudar seu rumo. Então o primeiro ponto a abordar é o caráter ideológico do cooperativismo. Sobre este aspecto, Rios (1989) chama a atenção para a recuperação do termo "cooperativa", para servir aos interesses das classes dominantes e da sua utilização como instrumento de controle, no lugar de mudança social. Hoje, vemos ainda fortes reflexos dessa postura ideológica, quando muitos defendem o cooperativismo como alavanca de mudanças das estruturas sociais, e em seu nome arrancam empréstimos e subvenções, para depois o Estado cobrir os prejuízos. Isto acontece porque, em geral, os bancos privados não emprestam a este tipo de organização. Geralmente, a esquerda entra com o discurso e a direita se aproveita dos recursos. A este respeito, muitos argumentam utilizando-se de uma tipologia entre as falsas e as verdadeiras cooperativas, um argumento ad hoc para justificar uma situação em que todos pagam para poucos, que nem são necessariamente os mais pobres.

Este aspecto ideológico de sustentação do cooperativismo justifica a presença do Estado como financiador direto ou indireto destas organizações, quer seja por meio de empréstimos subvencionados, quer seja por meio de da isenção de impostos, gerando uma concorrência privilegiada com as organizações não subvencionadas. Mas tudo isto poderia ser apenas uma disputa por verbas públicas, em que a população estivesse alheia, como em tantas outras ocasiões tem ocorrido. Entretanto, e este é o dado revelador da pesquisa, existe arraigada na população uma percepção de que as cooperativas e o cooperativismo são instrumentos legítimos de atuação subvencionada, porque são palavras agregadas de valores socialmente positivos, de maneira que suplantam as evidências de fracasso, dando respaldo e legitimidade tanto ao discurso ideológico, quanto à prática que absorve do Estado, recursos que poderiam ser aplicados em outras instâncias e com melhores resultados.

Contudo, também existem fatores de ordem psicossocial que podem influenciar no fracasso ou nas dificuldades em administrar este tipo de organização, pois se referem à produtividade grupal. Neste sentido, os conhecimentos desenvolvidos no campo da facilitação social; os estudos sobre o impacto que podem ter os "outros", mesmo sendo a mera presença, na produção e solução de tarefas no grupo, de longa tradição na psicologia social experimental, podem ser adequadamente utilizados na solução de problemas na produtividade das cooperativas.

A esse respeito, podem-se citar três aspectos críticos: a distribuição dos resultados, a distribuição das informações e a distribuição das respostas (Kelley \& Thibaut, 1968). Sobre esta última variável, nota-se facilmente seu efeito no processo de tomada de decisões pelo grupo, pelos membros que o constituem. Como os sócios compreendem a cooperativa como de todos, com direitos e responsabilidades iguais, pode dar lugar à ocorrência do fenômeno de difusão de responsabilidades (Darley \& Latané, 1968), em que todos esperam que o próximo seja quem deva tomar a decisão em assumir o ônus do trabalho ou da organização. Provavelmente, esta variável está por trás de muitas queixas e fracassos de cooperativas. Nesse sentido, os trabalhos empreendidos na linha da facilitação social, por Darley e Latané (1968) e Latané (1981), em torno do conceito de "preguiça social", podem subsidiar a resolução de problemas nas cooperativas. Ainda é importante destacar que nem sempre o comportamento cooperativo resulta num nível de resultados satisfatórios para o grupo, visto que depende do grau que a tarefa exige de atividade coordenada (Gahagan, 1976). Além disso, pode-se verificar que nem sempre as pessoas são proclives a cooperar. Alguns experimentos na psicologia social, acerca desta variável, mostraram que mesmo em situações nas quais a cooperação produzia mais benefícios para os grupos, os seus membros preferiam competir ao invés de cooperar (Freedman, Carlsmith \& Sears, 1970). O estudo sistemático destas variáveis, com efeito, pode jogar luz para o entendimento dos processos grupais nas cooperativas, ao mesmo tempo em que abrem uma avenida para a realização de pesquisas que testem as relações de importantes fatores para o impacto social, que visem compreender variáveis que facilitem a produtividade e que, concomitantemente, detectem aquelas que estariam gerando inibição da produtividade no grupo. Este é um forte campo de pesquisa fundamental e de aplicação para a psicologia social.

No que se refere aos conceitos de rural e urbano, à palavra rural se encontram relacionadas outras que demonstram 
uma compreensão desse ambiente como se fosse um bloco monolítico e compreendendo elementos próprios do agrário, como comentado em trabalho anterior (Albuquerque, 2001). Isto pode ser ratificado quando se observa o núcleo da rede do conceito de urbano. Nota-se a tendência a dicotomizar esses ambientes como se fossem totalmente opostos e como se fosse inconcebível a interseção de alguns elementos. Reflete-se, assim, o senso comum que ainda não consegue visualizar um ambiente rural no qual a industrialização já chegou, mesmo que ainda de forma tímida, por meio da presença de fábricas, pequenas empresas e serviços mais "sofisticados", entre outros avanços. Não se consegue ainda pensá-lo como um ambiente capaz de lidar com outros tipos de atividades que não sejam a agricultura e/ou pecuária. Percebeu-se que a imagem que os estudantes têm do rural ainda é eminentemente campestre ou rurícola. Possivelmente eles refletem a imagem que todos têm, inclusive os agentes responsáveis em deliberar políticas públicas, o que significa que os planos de desenvolvimento rural tendem a destinar mais incentivos para esta parte agrária do que para atividades voltadas para os setores de indústria ou de serviços. Ou seja, ao invés de se incentivar atividades como a criação de pequenas indústrias de transformação ou a formação de serviços, ainda se pensa na parte mais primária da produção, justamente aquela que tem mais dificuldade de desenvolver-se, talvez por ser a que menos valor agrega aos produtos. Disso se aproveitam, muitas vezes, latifundiários ou grupos empresariais, em detrimento daqueles que realmente necessitam dessas subvenções. Reputa-se que financiar um hectare de cana-de-açúcar é tão importante para o desenvolvimento local quanto uma banda de rock ou de forró. $\mathrm{O}$ que realmente importa é a geração de emprego e renda, de maneira que permita aos cidadãos, principalmente aos jovens, a permanência em seus ambientes com qualidade de vida. Como efeito realmente benéfico, isto pode gerar a diminuição do afluxo para os grandes centros, por si só superlotados de suas próprias mazelas e pelo fato de se poder contar com uma política adequada, trazer de volta aqueles que por necessidade partiram e que, sem opção, ali permanecem.

\section{Conclusão}

Conforme se verificou nesta pesquisa, a técnica de redes semânticas naturais pode figurar em estudos sobre ferramentas metodológicas de investigação no meio rural, podendo instigar novas investigações sobre conceitos vinculados ao desenvolvimento rural. Estes estudos, em que se averigua o processo de formação de conceitos, tomam parte nos principais interesses dos cientistas cognitivos (Gardner, 1996; Thagard, 1998). Ademais, os resultados das redes dos conceitos tratados também podem auxiliar na construção de instrumentos de medida para survey, em que se pretenda, por exemplo, mensurar atitudes frente ao ambiente rural e/ou aos moradores desse ambiente. Para maiores detalhes sobre a construção de escalas psicométricas, apoiada na técnica de redes semânticas, pode-se consultar Reyes-Lagunes (1993) ou Medina (1993), que, numa perspectiva etnopsicológica, serve-se dessa técnica para a construção de uma escala de autoconceito para mexicanos.

Esse tipo de pesquisa, que objetiva uma aproximação conceitual, deve ser estimulado quando se conhece pouco de um tema na psicologia social, como é o caso do ambiente rural e das organizações cooperativas. Apesar de se apresentarem resultados que indicam possibilidades de pesquisas futuras, deve-se assinalar, todavia, que esse tipo de investigação ainda é muito incipiente no Brasil. Por conseguinte, carece-se de um maior número de comparações que possam estabelecer resultados mais representativos e fidedignos.

De acordo com os dados coligidos, sugerem-se pesquisas de avaliação acerca das cooperativas, pois, como sugere Albuquerque (2002), elas estão mais propensas ao fracasso do que ao êxito. Autores que defendem este tipo de organização não apresentam dados empíricos que a suportem (Singer, 1998), de modo que os financiamentos que são dirigidos a essas organizações poderiam estar cumprindo melhor seu papel se fossem destinados a outros setores, como saúde, educação pública e serviços para atendimento ao cidadão, incentivando, por exemplo, novos vetores da economia no mundo rural, desde pequenos comércios até grupos culturais ou musicais. Disso poderia resultar um duplo benefício, que se traduz em melhores condições para a fixação de trabalhadores engajados no desenvolvimento do meio rural e, conseqüentemente, na diminuição da super concentração nas médias e grandes cidades, com o caos social que isto acarreta.

\section{Referências}

Abdounur, O. J. (2002). Matemática e música: O pensamento analógico na construção de significados. São Paulo: Editora Escrituras.

Albuquerque, F. J. B. \& Mascareño, R. M. P. (2001). Considerações não-ortodoxas sobre as cooperativas e o cooperativismo. Psicologia e Sociedade, 1(1), 41-61.

Albuquerque, F. J. B., Lôbo, A. L. \& Raymundo, J. S. (1999). Análise psicossociais das repercussões decorrentes da concessão de benefícios rurais. Psicologia: Reflexão \& Crítica, 12(2), 503-519.

Albuquerque, F. J. B. (1994). Estudio del cooperativismo agrario desde la perspectiva de la Psicologia Social. Tesis Doctoral: Universidad Complutense de Madrid, Madrid.

Albuquerque, F. J. B. \& Cirino, C. S. (2001). Expectativas dos sócios e técnicos sobre as cooperativas agrárias. Revista de Psicologia Organizações e Trabalho, 1(2), 73-96.

Albuquerque, F. J. B. (1997). Aspectos psicossociais das Cooperativas agrárias. Trabalho, Organizações e Cultura. São Paulo: Estação das Artes.

Albuquerque, F. J. B. (2001). Aproximación metodológica desde la psicología social a la investigación en zonas rurales. Revista Española de Estudios Agrosociales y Pesqueros, 191(1), 225233.

Albuquerque, F. J. B. (2002). Psicologia social e formas de vida rural no Brasil. Psicologia: Teoria e Pesquisa, 18(1), 37-42.

Berry, K. A., Markee, N. L., Fowler, N. \& Giewat, G. R. (2000). Interpreting what is rural and urban for western U.S. counties. Professional Geografer, 52(2), 93-105.

Bracham, R. V. (1979). What's in a concept structural foundations of semantics networks. International Journal of Man-Machines Studies, 1(2), 127-152.

Darley, J. M. \& Latané, B. (1968). Bystander intervention in emergencias: difusión of responsability. Journal of Personality and Social Psychology, 8(3), 377-383. 
Echebarría, A. (1991). Psicologia social sociocognitiva. Bilbao: Desclée de Brouwer.

Estramiana, J. L. (1995). Psicología social: Perspectivas teóricas y metodológicas. Madrid: Siglo Veintiuno de España Editores.

Figueroa, J. G. González, E. G. \& Solís, V. M. (1981). Uma aproximação ao problema dos significados: as redes semânticas. Revista Latinoamericana de Psicologia, 13(2), 447-458.

Fiske, S. T. \& Taylor, S. E. (1991). Social cognition. New York: McGraw Hill.

Freedman, J. L., Carlsmith, J. M. \& Sears, D. O. (1970). Psicologia social. São Paulo, SP: Cultrix.

Gahagan, J. (1976). Comportamento interpessoal e de grupo. Rio de Janeiro, RJ: Zahar Editores.

Gardner, H. (1996). A nova ciência da mente. São Paulo, SP: Edusp.

Grzib, G. \& Briales, C. (1996). Psicología general. Madrid: Editorial Centro de Estudios Ramón Areces.

Howitt, D., Billig, M., Cramer, D., Edwards, D., Kniveton, B., Potter, J. \& Radley, A. (1992). Social psychology: Conflicts and continuities. Milton Keynes: Open University Press.

Instituto Brasileiro de Geografia e Estatística. (2002). Anuário estatístico do Brasil. Retirado em 13/09/2002, http://www. ibge.gov.br.

Jacinto, L. G. \& Ortiz, J. M. C. (1997). Psicología social. Madrid: Ediciones Pirámide.

Kelley, H. H. \& Thibaut, J. W. (1968). Group problem solving. Em G. Lindzey \& E. Aronson (Orgs.), The handbook of social psychology (pp. 1-101). California: Addison-Wesley.

Krech, D., Crutchfied, R. S. \& Ballachey, E. L. (1975). O indivíduo na sociedade. (D. M. Leite \& M. L. M. Leite, Trads.). São Paulo: Pioneira.

Lachman, R., Lachman, L. \& Butterfield, E. (1979). Cognitive psychology information processing: An introduction. New Jersey: LEA Publishers.

Latané, B. (1981). The psychology of social impact. American Psychologist, 36, 343-356.

Medina, J. L. V. (1993). La construcción de instrumentos de medición a partir de categorías semánticas. Un caso ilustrativo: El autoconcepto. Revista de Psicología Social y Personalidad, 11(1), 57-66.

Morales, J. F., Moya, M., Rebolloso, E., Dols, J. M. F, Huici, C., Marques, J., Páez, D. \& Pérez, J. A. (1994). Psicologia social. Madrid: McGraw-Hill.

Mussen, P. H., Conger, J. J., Kagan, J. \& Huston, A. C. (1995). Desenvolvimento e personalidade da criança. São Paulo: Harbra.
Pariguin, B. D. (1972). A Psicologia social como ciência. Rio de Janeiro: Zahar Editores.

Reyes-Lagunes, I. (1993). Las redes semânticas naturales, su conceptualización y su utilización en la construcción de instrumentos. Revista de Psicología Social y Personalidad, 1(1), 81-97.

Rios, G. S. L. (1989). O que é cooperativismo. São Paulo: Brasiliense.

Roazzi, A. (1999). Pesquisa básica em psicologia cognitiva e sua relação com a psicologia social. Arquivos Brasileiros de Psicologia, 51(1), 23-54.

Rodrigues, A., Assmar, E. M. L. \& Jablonski, B. (2000). Psicologia social. Petrópolis, RJ: Vozes.

Sabucedo, J. M., D’Adamo, O. D. \& Beaudoux, V. G. (1997). Fundamentos de psicología social. Madrid: Siglo Veintiuno de España Editores.

Singer, P. (1998). Globalização e desemprego: Diagnóstico e alternativas. São Paulo: Contexto.

Smith, E. R. \& Mackie, D. M. (1995). Social psychology. New York, NY: Worth Publishers.

Sternberg, R. J. (2000). Psicologia cognitiva. Porto Alegre: ArtMed.

Thagard, P. (1998). Mente: Introdução à ciência cognitiva. Porto Alegre: ArtMed.

Tulving, E. (1972). Episodic and semantic memory. Em E. Tulving \& W. Donaldson (Orgs.), Organization of memory (pp. 381403). New York: Academic Press.

Turner, J. C. (1994). El campo de la psicologia social. Em J. F. Morales (Org.), Psicologia social (pp. 3-21). Madrid: McGrawHill/Interamericana de España.

Vera-Noriega, J., Laga-Castro, A. \& Hernández-Loyola, F. (1998). Redes semanticas de los conceptos asociados a la relación de pareja. Estúdios Sociales, 16(2), 109-126.

Zajonc, R. (1968). Cognitive theories in social psychology. Em G. Lindzey \& E. Aronson (Orgs.), The handbook of social psychology (pp. 320-411). California: Addison-Wesley.

Recebido em 06.06.2003

Primeira decisão editorial em 16.06.2004

Versão final em 15.07.2004

Aceito em 25.07.2004 